4. Кузнецов, В.В., Рыбкина, М.В. Сущность и принципы социального партнёрства в сфере труда [Текст] / В.В. Кузнецов, М.В. Рыбкина // Вестник УлГТУ. - 2016. - №3 (75). С 70-73.

5. Михеев, В.А. Основы социального партнерства: теория и политика [текст] : учебник для вузов. / В.А. Михеев; Москва: Экзамен. - 2001 - 448 с.

6. Потемкин, В.К., Казаков, Д.Н. Социальное партнерство: формирование, оценка, регулирование [Текст] / В.К. Потемкин, Д.Н. Казаков // СПб.: РАЕН, 2002. С. 16.

7. Рашидова, А. И. Социальное партнерство в сфере труда как категория зрелой рыночной экономики [Текст] / А.И. Рашидова // Вопросы структуризации экономики. - 2012. - №3. С. 225226.

8. Тиховодова, А. В. Социальное партнерство: сущность, функции, особенности развития в России [Текст] / А.В. Тиховодова // Известия РГПУ им. А.И. Герцена. - 2008. - №58. С. 297- 301

\title{
Коростиев А.А. \\ Базельский комитет по банковскому надзору: правотворчество и ответственность
}

Дальневосточный федеральный университет (Россия, Владивосток)

doi: $10.18411 / l j-02-2021-210$

idsp: ljournal-02-2021-210

\section{Аннотация}

На разных этапах экономического развития выделялись регуляторы финансовой системы. Они отличались помимо прочего, своими уникальными функциями, а также поставленными перед ними государством и обществом задачами. В статье проводится анализ одного из таких регуляторов макроуровня - Базельского комитета. Проводится краткий анализ трех Базельских стандартов. Рассмотрено влияние Базельских соглашений на банковскую систему Российской Федерации. В результате исследования обоснованы выгоды от применения данных соглашений.

Ключевые слова: Базельский комитет по банковскому надзору, Базель I, Базель II, Базель III, Базельский стандарт, банковский надзор, банковская система, страны группы десяти (G10), мегарегулятор, пруденциальная политика, кредитный риск, собственные средства банка, пруденциальное банковское регулирование.

\section{Abstract}

At different stages of economic development, various regulators of the financial system existed. They were delivered separately from each other, with their unique capabilities. The article analyzes one of such regulators at the macro level - the Basel Committee. A brief analysis of the three Basel standards is carried out. The influence of the Basel institutions on the banking system of the Russian Federation is considered. As a result of the study, these applications are reasonably applied.

Keywords: Basel Committee on Banking Supervision, Basel I, Basel II, Basel III, Basel Standard, banking supervision, banking system, countries of the Group of Ten (G10), mega-regulator, prudential policy, credit risk, own funds of the bank, prudential banking regulation.

На сегодняшний день Базельский комитет по банковскому надзору представляет собой уникальную организацию, действующую при Банке международных расчетов. При этом он не является структурным подразделением Банка международных расчетов и действует автономно. Базельский комитет является международным финансовым мегарегулятором, осуществляющим пруденциальную политику, наряду с такими организациями, как МВФ, Совет по финансовой стабильности, Банк международных расчетов.

Базельский комитет был основан президентами центральных банков стран группы десяти (G10) в 1974 году в Базеле. По состоянию на сегодняшний день членами 
Базельский комитет являются 28 ведущих стран мира, в том числе Россия. В качестве стран-наблюдателей представлены Чили, Малайзия и ОАЭ. Также участвуют на правах наблюдателей в работе Комитета - Европейская служба банковского надзора, Европейская комиссия, Институт финансовой стабильности, а также Международный валютный фонд.

Главной задачей Базельского комитета является разработка и внедрение стандартов в регулировании деятельности финансово-кредитных учреждений в виде Базельских соглашений, которые являются обязательными, отображаются в нормативно-правовых и законодательных актах стран [6, С. 244].

Помимо этого, Базельский комитет осуществляет международный надзор, контролирует международные банковские операции, а также предоставляет краткосрочные кредиты центральным банкам [8, C. 112].

Основной целью Базельского комитета является устранение недочетов и разногласий в банковском регулировании на международном уровне, а также выработка совместных принципов развития и сближения национальных подходов в области регулирования банковской деятельности. В рамках Базельских соглашений обобщается и стандартизируется практика банковского дела.

Необходимо отметить, что все национальные регуляторы банковских систем стран-участниц Базельского комитета, в том числе Банк России, проводят свою политику в соответствии с рекомендациями Комитета.

Первым успешным плодом сотрудничества стран-участниц Базельского комитета стал Базель I или «Международное сближение методов измерения и стандартов капитала». Он был разработан в 1988 году и предполагал соблюдение следующих нормативов и правил:

— минимальный размер достаточности капитала банка, устанавливается в размере $8 \%$ от суммы активов и забалансовых статей. Другими словами, собственные средства банка должны составлять не менее $8 \%$ его активов. Если это значение становится ниже 2\% (абсолютное снижение норматива достаточности капитала), то в соответствии с Российским законодательством Центральный Банк обязан отозвать лицензию у банка, нарушившего данное требование [9]. При абсолютном снижении величины собственных средств (капитала) по сравнению с их максимальной величиной, достигнутой за последние 12 месяцев, более чем на 20\% при одновременном нарушении одного из обязательных нормативов, установленных Банком России, центральный банк может применить к нему одну из мер по предупреждению банкротства;

- деление активов по степени риска на четыре группы, с помощью весовых коэффициентов. Таким образом определяются кредитные риски на основе взвешенной оценки. Данные весовые коэффициенты являются исключительной компетенцией регуляторов национальных банковских рынков;

- деление капитала на два уровня: 1 уровень состоит из акционерного капитала и объявленных резервов; 2 уровень из дополнительного капитала, к которому относят капитал низкого качества, а также скрытые резервы, доступные для банка в соответствии с законодательством страны и т. д.

- условие о том, что капитал второго уровня не должен превышать 50\% от капитала первого уровня;

- условие о величине собственного капитала, которая должна быть не менее 5 млн. евро. 
Формула, предложенная в первом Базельском соглашении, по которой оценивалась достаточность капитала выглядела следующим образом:

$$
\mathrm{RWA}=\mathrm{CRWA}+\mathrm{MR}
$$

где CRWA - активы, взвешенные с учетом степени кредитного риска, MR - рыночный риск.

Достаточность капитала рассматривалась как главный критерий стабильности банковской деятельности, а также позволяла оградить отдельно взятый банк от убытков.

По существу требования к капиталу банка, а также требования к достаточности капитала банка являются основополагающими экономическими нормативами, т.е. основными инструментами пруденциального банковского регулирования.

Именно Базель I ввел требования к достаточности собственного капитала кредитной организации к сумме активов, взвешенных с учетом кредитного риска, в размере $8 \%$, что, собственно, и стало первой ступенью как к оценке рисков и активов банков, так и к расчету достаточности капиталов банков.

Если говорить об ответственности за неисполнения требования по нормативу достаточности капитала, то в случае нарушения нормативов, а также представление недостоверной информации, непредставление информации являются основанием применения мер воздействия в рамках банковского надзора [4]. В частности, Банк России имеет право требовать от кредитной организации устранения выявленных нарушений, взыскивать штраф в размере до 0,1 процента минимального размера уставного капитала, либо ограничивать проведение кредитной организацией отдельных операций.

Таким образом, размер собственных средств (капитала) кредитной организации является важнейшим показателем ее финансовой устойчивости. Прошедшая в 2017 г. реформа по выделению банков с универсальной и базовой лицензиями кардинально не изменила значение поддержания показателя достаточности собственного капитала банка как ключевого показателя его финансовой стабильности.

Однако помимо достоинств, первое Базельское соглашение имеет и ряд недостатков, таких как:

- игнорирование остальных видов банковского риска;

- уделение внимания лишь регулированию кредитного риска;

- упрощенная градация кредитного риска, не учитывающая разнообразие возможных реальных ситуаций.

В связи с этими недостатками в 2004 году было выпущено обновленное соглашение - Базель II или «Международная конвергенция измерения капитала и стандартов капитала: новые подходы» [1].

К числу нововведений относят:

- добавление весового коэффициента $150 \%$ оценки кредитного риска;

- введение компонента рыночной дисциплины. Данный компонент содержит обновленное требование по раскрытию банками информации о системе управления рисками и капиталом. В соответствии с Указание Банка России от 07.08.2017 № 4481-У "О правилах и сроках раскрытия головными кредитными организациями банковских групп информации о принимаемых рисках, процедурах их оценки, управления рисками и капиталом и о финансовых инструментах, включаемых в расчет собственных средств (капитала) банковской группы", головные кредитные организации банковских групп раскрывают информацию в интернете о рисках на консолидированной основе ежегодно, ежеквартально, а также каждые полгода; 
- повышение минимальных требований к капиталу. В частности, увеличилось требование к объему капитала второго уровня. Теперь он не должен превышать 100\% капитала первого уровня;

- проверка сведений теперь осуществляется не за один год, а за более продолжительный период;

- расширение роли органов надзора;

- оценка и проверка внутреннего капитала. При этом вводились дополнительные показатели достаточности, которые позволили улучшить точность оценки подверженности рискам;

- добавлены «Стандартизированный подход» и «Подход внутреннего рейтинга» к оценке кредитного риска.

Стандартизированный подход состоял в том, что бизнес банка делился на восемь направлений, при этом каждому направлению присваивался определенный коэффициент риска:

- 18\% присваивается операциям на финансовых рынках, платежам и расчетам, корпоративному финансированию;

- $15 \%$ обслуживанию юрлиц, агентским услугам;

- $12 \%$ розничным банковским услугам, управлению активами, брокерским услугам.

Помимо этого, стандартизированный подход предполагает взвешивание величины кредитных требований на коэффициент, присваиваемый тому или иному заемщику в зависимости от внешнего кредитного рейтинга, определенного тем или иным международным рейтинговым агентством, например Standard \& Poor's, Fitch или Moody's.

Повышение рыночной дисциплины закрепилось в обязанности банками по раскрытию информации о своей деятельности (Market discipline). Банки, получившие одобрение от органов надзора, могли применять подход внутреннего рейтинга (Internal rating based approach - IRВ-подход).

IRB подход состоит в том, что банки могут полагаться на свои собственные внутренние оценки компонентов риска. Компоненты риска включают показатели вероятности дефолта (PD), удельного веса убытков в случае дефолта (LGD), стоимости под риском дефолта (EAD) и эффективных сроков погашения (M). Однако в некоторых случаях банки обязаны использовать данные органов надзора, а не свои внутренние оценки [1, С. 55]. Например, банк использует внутренний показатель вероятности дефолта (PD) контрагента, а в отношении других компонентов кредитного риска (LDG, $\mathrm{EAD}, \mathrm{M})$ руководствуется рекомендациями регулятора. Таким образом IRB подход позволяет самостоятельно определить величину взвешенных по риску активов.

Продвинутый подход (Advanced IRB) основан на самостоятельном определении банками всех четырех показателей кредитного риска, при условии соблюдения минимальных требований, предусмотренных Базелем II.

Внедрение Базеля II в различных государствах СНГ находится на разных стадиях. Некоторые из государств, такие как Российская Федерация, Казахстан и Армения, находятся уже на продвинутой стадии внедрения третьего пакета стандартов, а некоторые государства, такие как Кыргызская Республика или Таджикистан, лишь сейчас завершают окончательную имплементацию норм Базель II [3].

Таким образом, второе Базельское соглашение предлагает более взвешенный и разносторонний подход к оценке достаточности собственного капитала.

К недостаткам Базеля II относят:

- неразвитость института внешних рейтинговых агентств во многих странах; 
— различия в оценках одного и того же заемщика разными рейтинговыми агентствами;

- допускал концентрацию кредитного риска в одном секторе экономики;

- присутствовала платность процедуры рейтингования, что могло привести к искажению оценки реальной кредитоспособности заемщика;

- ответственность за оценку кредитных рисков несли рейтинговые агентства, не подконтрольные органам банковского надзора, что в итоге привело к завышению рейтинга ссудозаемщиков, т.е. к недооценке кредитного риска.

Видно, что требования, предъявленные Базелем II к процессу внешнего рейтингования завышены и носят, зачастую, декларативный характер. В нынешних условиях, необходимо отметить, что ведущим должен стать именно Advanced IRB продвинутый подход внутреннего рейтинга, без привлечения международных рейтинговых агентств.

Как показывает практика, потребность в капитале увеличивается во время экономических спадов и уменьшается в период экономических подъемов. Тому находит подтверждение финансовый кризис 2008 года, безусловно выявивший необходимость к глобальному реформированию банковского регулирования, что способствовало созданию третьего Базельского соглашения.

Основные акценты Базеля III были уделены изменению уже существующих рекомендаций:

— норматив достаточности по акционерному капиталу повышается с 2 до $4,5 \%$

- ликвидные активы капитала первого уровня увеличиваются с 4,5 до 6\%.

- внесена обязанность каждому банку создать специальный резервкапитал в размере 2,5 процента, а также стабфонд до 2,5 процентов капитала [5, С. 64];

- были созданы буферы капитала - резервный и антициклический. Такие буферы позволили скорректировать собственные средства кредитной организации для противодействия циклическим колебаниям в хозяйственной сфере;

- была внесена обязанность изъять из состава собственного капитала 1 уровня 15\%-ную «подушку», включающую отложенные налоги и секьюритизированные активы;

— c 2018 г. установлено ограничение финансового рычага (левериджа).

- вводится показатель краткосрочной ликвидности (ПКЛ) и показатель чистого стабильного фондирования (ПЧСФ или Н28, Н29).

Реакцией на введение третьего Базельского соглашения в том числе стала Инструкция Банка России от 29.11.2019 N 199-И, закрепляющая минимальные допустимые значения нормативов в соответствии с Базельскими [2]:

- норматив достаточности базового капитала (Н1.1) устанавливается в размере $4,5 \%$;

- норматив достаточности основного капитала (Н1.2, капитал первого уровня) в размере $6 \%$

- норматив достаточности собственных средств капитала (H1.0, совокупный капитал) устанавливается в размере $8 \%$.

В Российской Федерации на данный момент действует Положение О методике определения собственных средств (капитала) кредитных организаций ("Базель III") от 04.07.2018 г. № 646-П, разработанное Центральным Банком Российской Федерации. Величина капитала банков в соответствии с указанной методикой определяется как сумма основного и дополнительного капитала. В состав источников собственных 
средств кредитной организации включается уставный капитал, состоящий из обыкновенных акций и привилегированных акций [7].

В соответствии с Федеральным Законом от 02.12.1990 № 395-1 "О банках и банковской деятельности" минимальный размер собственных средств (капитала) банка с базовой лицензией устанавливается в размере 300 млн. рублей. Если банк допустит в течение четырех месяцев подряд снижение этого размера, то в течение шести месяцев с даты истечения указанного периода должен будет изменить свой статус на статус небанковской кредитной организации или получить статус микрофинансовой компании с одновременным прекращением статуса кредитной организации и аннулированием лицензии на осуществление банковских операций [9].

Необходимо заметить, что принципы и стандарты, закрепленные в Базельских соглашениях, распространяют свое влияние на макроуровне. Это характеризуется тем, что рекомендации затрагивают банковские системы всех стран, присоединившихся к Комитету.

Новые версии Базельского соглашения в свою очередь не отменяют действия предыдущих, а дополняют и совершенствуют их. Таким образом, после введения в действия Базеля III, требования, введённые Базелем II, продолжают действовать.

Порядка 80\% всех российских банков имеют капитал в размере менее 10 млн. долларов. Кроме того, российские банки имеют разные финансовые показатели, разные программы управления стратегией. Большое значение имеют отсутствие активных методов, нацеленных на диверсификацию и модификацию бизнеса, способности адаптироваться к быстроменяющимся условиям. По состоянию на 16 марта 2020 г. на территории РФ 828 кредитных организаций имеют лицензии на осуществление банковских операций. Однако меньше $2 \%$ российских банков (это около 15 банков) из общего количества соответствуют Базелю III.

Статистические данные, проведенные АCB (агентством по страхованию вкладов), показывают что около 90\% изученных российских кредитных организаций приобрели признаки банкротства в результате неправомерных действий их руководителей, направленных на вывод из банка ликвидных активов, в остальных 10\% случаев причиной банкротства можно было бы назвать рыночные факторы, которые, однако, были усугублены отсутствием в этих банках капитала.

Кроме того, в марте 2016 г. по итогам проверки, проведенной Базельским комитетом по банковскому надзору, банковское регулирование в России было признано соответствующим минимальным стандартам Базеля. Это демонстрирует пока неготовность банковского сектора в России следовать по пути европейского вектора развития.

Пути решения данной проблемы видятся в следующем:

- банкам необходимо, прежде всего, в соответствии с рекомендациями, представлять информацию о своей деятельности;

- также необходимо придерживаться указаний Базельского комитета в части соблюдения требований пруденциальной политики;

- открыть доступ мегарегулятору ко всем портфельным денежным потокам;

— проводить стресс-тестирование кредитной организации по отношению к внутренним и внешним факторам;

- довести размер капитала до соответствующего уровня;

- повысить качество кредитного портфеля.

Третий базель - не последний документ в области банковского регулирования. Базельский комитет и в дальнейшем будет совершенствовать и редактировать уже существующие положения, а также добавлять новые рекомендации. 
Успешное применение Базельских соглашений не только повысит кредитоспособность банковских организаций, но и улучшит их устойчивость к кризисным ситуациям, что безусловно сыграет положительную роль в поддержании стабильного экономического рынка России.

Базельские принципы помогут крупнейшим российским банкам выйти на рынок внешних заимствований. При этом необходимо учитывать, что для выхода России на высокий международный уровень, банкам необходимо строго придерживаться Базельских соглашений, а не воспринимать их просто в качестве рекомендаций. Банк, внедривший в свою деятельность рекомендации Базельского комитета, будет восприниматься в качестве более надежного партнера при взаимодействии с иностранными инвесторами.

Таким образом, переход российских банков на Базель III безусловно повысит их репутацию на международном уровне, а также окажет благоприятное воздействие на национальную банковскую систему.

$$
* * *
$$

1. Базельский комитет по банковскому надзору. Международная конвергенция измерения капитала и стандартов капитала: уточненные рамочные подходы // Банк международных расчетов. Июнь 2004. URL: https://web.archive.org/web/20120617075545/http://www.cbr.ru/today/ms/bn/Basel.pdf (дата обращения: 19.06.2020).

2. Инструкция Банка России от 29.11.2019 № 199-И "Об обязательных нормативах и надбавках к нормативам достаточности капитала банков с универсальной лицензией" // "Вестник Банка России", № 11 - 12, 30.01.2020.

3. Исмаилов, И.Ш. Внедрение базельских стандартов банковской деятельности в Российской Федерации и странах СНГ // Банковское право. 2017. № 3. С. 65 - 69.

4. Лаутс, Е.Б. Снижение собственных средств (капитала) банка и меры по предупреждению банкротства: правовые аспекты взаимодействия // Банковское право. 2017. № 6. С. 39 - 46.

5. Логвиненко, В.Д. Корчагин, А.Г. Базельские стандарты в России // Теология. Философия. Право. 2017. № 3 (3). С. 59-72.

6. Никулина, О.В., Броварец А.К. Международное регулирование банковской деятельности: участие Базельского комитета в регулировании деятельности коммерческих банков // Инновационная экономика: перспективы развития и совершенствования. 2017. № 1 (19). С. 244-248.

7. Положение Банка России от 04.07.2018 № 646-П (ред. от 06.06.2019) "О методике определения собственных средств (капитала) кредитных организаций ("Базель III")" // "Вестник Банка России", № $75,28.09 .2018$.

8. Тургаева, А.А. Соответствие Российской банковской системы международным стандартам Базельских соглашений // Вестник АГТУ. Серия: Экономика. 2016. № 3. С. 110-116.

9. Федеральный закон от 02.12.1990 № 395-1 (ред. от 27.12.2019) "О банках и банковской деятельности" (с изм. и доп., вступ. в силу с 08.01.2020) // Собрание законодательства РФ, 05.02.1996, № 6, ст. 492.

\section{Коростиев А.А. \\ Особенности использования изображений граждан в рекламе и на товарах}

Дальневосточный федеральный университет (Россия, Владивосток)

doi: $10.18411 / l j-02-2021-211$

idsp: ljournal-02-2021-211

Научный руководитель

Рабеи А.П.

\section{Аннотация}

Изображения граждан в последнее время можно увидеть в самых различных ситуациях. Их публикуют в газетах, показывают на ТВ шоу, демонстрируют в фильмах, на рекламных баннерах, на товарах народного потребления (кружках, одежде и т.п.) и даже в товарных знаках. В силу таких обстоятельств возникают существенные вопросы 